\title{
Tumour-associated endothelial-FAK correlated with molecular sub-type and prognostic factors in invasive breast cancer
}

Annika N Alexopoulou', Colan M Ho-Yen², Vassilis Papalazarou ${ }^{3}$ George Elia², J Louise Jones² and Kairbaan Hodivala-Dilke ${ }^{1 *}$

\begin{abstract}
Background: Breast cancer is a heterogeneous disease that can be classified into one of 4 main molecular sub-types: luminal A, luminal B, Her2 over-expressing and basal-like (BL). These tumour sub-types require different treatments and have different risks of disease progression. BL cancers can be considered a sub-group of Triple negative (TN) cancers since they lack estrogen (ER), progesterone (PR) and Her2 expression. No targeted treatment currently exists for TN/BL cancers. Thus it is important to identify potential therapeutic targets and describe their relationship with established prognostic factors. Focal adhesion kinase (FAK) is upregulated in several human cancers and also plays a functional role in tumour angiogenesis. However, the association between breast cancer sub-types and tumour endothelial-FAK expression is unknown.
\end{abstract}

Methods: Using immunofluorescence, we quantified FAK expression in tumour endothelial and tumour cell compartments in 149 invasive breast carcinomas and correlated expression with clinical, pathological and molecular parameters.

Results: Low endothelial-FAK expression was independently associated with luminal A tumours at univariate $(p<0.001)$ and multivariate $(p=0.001)$ analysis. There was a positive correlation between FAK expression in the vascular and tumour cell compartments (Spearman's correlation co-efficient $=0.394, p<0.001$ ). Additionally, endothelial and tumour cell FAK expression were significantly increased in TN tumours $(p=0.043$ and $p=0.033$ respectively), in tumours with negative ER and PR status, and in high grade tumours at univariate analysis.

Conclusion: Our findings establish a relationship between endothelial-FAK expression levels and the molecular sub-type of invasive breast cancer, and suggest that endothelial-FAK expression is potentially more clinically relevant than tumour cell FAK expression in breast cancer.

Keywords: FAK, Endothelium, Breast cancer, Molecular sub-type

\footnotetext{
* Correspondence: k.hodivala-dilke@qmul.ac.uk

${ }^{1}$ Adhesion and Angiogenesis Laboratory, Centre for Tumour Biology, Barts Cancer Institute - a CR-UK Centre of Excellence, Queen Mary University of London, John Vane Science Centre, Charterhouse Square, London EC1M 6BQ, UK

Full list of author information is available at the end of the article
}

\section{Biomed Central}

(c) 2014 Alexopoulou et al.; licensee BioMed Central Ltd. This is an Open Access article distributed under the terms of the Creative Commons Attribution License (http://creativecommons.org/licenses/by/2.0), which permits unrestricted use, distribution, and reproduction in any medium, provided the original work is properly credited. 


\section{Background}

Breast cancer is a heterogeneous disease which, according to extensive gene expression profiling, can be grouped into 4 major categories: luminal A, luminal B, human epidermal growth factor receptor-2 oncogene (also called Her2/ ERBB2) type and basal-like breast cancer [1,2]. Each tumour type requires different treatment, has a different risk of disease progression and distinct patterns of metastasis [3]. Therefore, ER tumours are treated using antiestrogen based therapies such as tamoxifen or aromatase inhibitors and Her2 over-expressing tumours can be targeted with the anti-Her2 therapy trastuzumab. The aggressive basal-like (BL) tumours can be considered a sub-group of triple negative (TN) tumours since most are negative for ER, PR and Her2 [4,5]. TN/BL cancers have a poor prognosis in comparison to other molecular sub-types and targeted molecular therapies are not currently available for patients with these tumours. Thus identifying new therapeutic targets becomes a priority for TN/BL cancers.

Focal adhesion kinase (FAK) is a $125 \mathrm{kDa}$ non-receptor tyrosine kinase that can be activated both by integrins and extracellular stimuli such as growth factors [6,7]. FAK is involved in, and regulates, several key cell processes in cancer progression and tumour angiogenesis including cell survival and apoptosis, adhesion, migration and invasion.

In human cancers, increased tumour cell FAK expression has been shown in several cancer types including lung, cervical, colon and breast when compared to normal tissue [8-12]. In non-small-cell lung cancer high tumour cell FAK expression was found to correlate with increased lymph node metastasis and decreased survival [8]. Other studies have shown that cancer cell FAK expression and activation are linked with malignant transformation but not with an invasive phenotype in breast carcinomas [13]. Interestingly, endothelial-FAK expression in astrocytic tumours was increased in higher grade tumours [14].

Understanding the in vivo role of FAK has been aided by genetic ablation studies in mice. Loss of epidermal FAK can reduce tumour progression [15]. Additionally, endothelial specific FAK-kinase domain inactivation is associated with reduced vascular leakage [16]. Moreover, endothelial-FAK deletion has been shown to inhibit tumour growth due to a defect in tumour angiogenesis initiation [17]. In contrast, FAK-heterozygous mice, that have half the normal levels of FAK, display elevated xenograft tumour growth [18]. Together these results suggest that endothelial-FAK levels may affect tumour size. Despite these studies no data is available presently to link endothelial-FAK levels with prognostic factors in human breast cancer.

The increased expression of FAK in many cancer types has stimulated the development of FAK inhibitors for the treatment of cancer [19]. Given the critical role of this molecule in both the tumour and endothelial cell compartment, an analysis of the relationship between expression and clinicopathological factors would be beneficial in the design of future clinical trials targeting FAK.

The purpose of this study was to determine whether FAK expression in the endothelial cell or tumour cell compartment of invasive breast carcinomas correlates with established clinicopathological characteristics, or differences between molecular sub-types.

\section{Methods}

\section{Tissue specimens}

Formalin-fixed and paraffin-embedded blocks of surgically resected invasive breast cancers from 149 patients were provided by the Barts Cancer Institute Breast Tissue Bank, following informed patient consent (ethics ref:10/H0308/ 49). The clinicopathological characteristics (age at presentation, tumour size, tumour grade, lymph node status, and ER/PR/Her2 status) were obtained from the diagnostic histopathology reports. The tumours were allocated into molecular sub-types using the following biomarker profile: 'luminal A' (ER and/or PR+, Her2-), 'luminal B' (ER and/ or PR+, Her2+), 'Her2-positive' (ER-, PR-, Her2+) and 'triple negative' (ER-, PR-, Her2-) [20]. This study followed REMARK guidelines for tumour marker prognostic studies [21].

\section{Immunofluorescence analysis}

Sections were dewaxed in xylene and blocked in 3\% $\mathrm{H}_{2} \mathrm{O}_{2}$ solution in methanol to block endogenous peroxidases. Antigen retrieval was performed by heating sections in $10 \mathrm{mM}$ Sodium Citrate buffer. Samples were then blocked with protein block/serum free (Dako, Cambridgeshire, UK) and incubated with anti-FAK clone 4.47 (Millipore, Massachusetts, USA) and anti-PECAM antibodies (Millipore) overnight at $4^{\circ} \mathrm{C}$. Mouse and rabbit IgGs (Dako) were used as a negative control for the antiFAK and anti-PECAM antibodies. After incubation with the primary antibodies, tissue sections were washed three times in PBS followed by 60 minutes incubation at room temperature with anti-mouse biotinylated and anti-rabbit Alexa 546 (Invitrogen Molecular Probes, Paisley, UK) antibodies. After washing with PBS, tissue sections were incubated with streptavidin-HRP for 30 minutes at room temperature (TSA/fluorescein systems; PerkinElmer, Massachusetts, USA). They were then washed with PBS and incubated for 5 minutes at room temperature with Fluorescein Tyramide solution (TSA/fluorescein systems). The sections were mounted using Prolong Gold Antifade reagent with DAPI (Invitrogen Molecular Probes, Paisley, UK). Fluorescence was analysed using the epifluorescent Zeiss Axioplan Microscope (Carl Zeiss, Germany). 


\section{Scoring immunohistochemistry}

For each case, images covering $75 \%$ to $100 \%$ of the tissue section were acquired. Each image was scored for FAK expression in tumour cells based on a scoring system that measured both percentage of positive cells $(0$, none; $1,<25 \% ; 2,25-50 \% ; 3,50-75 \% ; 4,>75 \%)$ and intensity of staining ( 0 , none; 1 , weak; 2 , moderate; 3 , strong). The sum of these values provided a score ranging from $0-7$ for each image. A mean score was then calculated for each case. In addition, each image was scored for FAK expression in tumour endothelium based on a scoring system that measured the intensity of FAK staining in each vessel ( 0 , none; 1 , borderline; 2 , weak; 4 , moderate; 6 , strong) and took into account the percentage of positive cells per vessel. If $<20 \%$ of the endothelial cells in a vessel were positive for FAK this vessel was assigned half of the intensity value of the positive cells. This system provided possible outcomes of 7 categories $(0,0.5,1,2$, $3,4,6)$ for each blood vessel of every case. The intensity of staining was multiplied by the percentage of vessels with that score. These values were then summed to give a total score for all vessels ranging from 0 to 600 . The vessels analysed had a diameter $\geq 5 \mu \mathrm{m}$ and were $<100 \mu \mathrm{m}$ distance from tumour cells. The median number of vessels scored per case was 44 . The samples were scored by one person in a blinded manner. To validate the score for FAK expression, 10 tumour samples were stained and scored twice on different days, providing similar scores.

\section{Statistical analysis}

FAK expression scores for both tumour cells and blood vessels were considered as non-parametric continuous variables since neither follows a normal distribution. The correlation between FAK expression and continuous variables was performed using Spearman's correlation co-efficient and the Mann-Whitney $U$ test was performed to assess possible associations between FAK expression and categorical variables. The correlation between FAK expression and molecular sub-type was carried out using univariate and multivariate logistic regression with forward step-wise entry. In the regression analysis, to facilitate comparison between tumour cell and endothelial cell FAK, scores were re-scaled to give a score between 0 and 1 . Scores were re-scaled by dividing the parameter score by its maximum value, so for example a raw score of 600 would be rescaled to $600 / 600=1$. Alternatively, a score of 200 would be rescaled to $200 / 600=0.33$. A two-sided p-value less than 0.05 was considered statistically significant. Statistical analyses were performed with SPSS statistical software, Version 19.0 (IBM Corp., Armonk, New York, USA) and GraphPad Prism, Version 4.0 (GraphPad Software Inc., La Jolla, CA, USA).

\section{Results}

Patient and tumour characteristics

Of the 149 patients included in this study, 129 had invasive ductal carcinoma, no special type, 15 had invasive lobular carcinoma, 2 had invasive micropapillary carcinoma and there was one patient each with mucinous, metaplastic and apocrine carcinoma. The mean age at presentation was 56.6 years and the mean tumour size was $26.6 \mathrm{~mm}$. Grade 3 tumours accounted for $61 \%$ of the cohort and $48 \%$ of the patients had lymph node involvement. The luminal A sub-type was the most common, accounting for $38 \%$ of tumours. The percentage of tumours with positive ER, PR and Her2 status was 58\%, $53 \%$ and $8 \%$ respectively. The clinicopathological features of the cohort are summarized in Table 1.

\section{Correlation between endothelial and tumour cell FAK expression}

There was a positive correlation between FAK expression in the vascular and tumour cell compartments (Spearman's correlation co-efficient $=0.394, \mathrm{p}<0.001$ ). Representative immunofluorescent images of FAK expression in the tumour endothelial and cancer cell compartments in luminal A (Figure 1A-D), luminal B (Figure 1E-H), Her2-overexpressing (Figure 1I-L) and Triple Negative (Figure 1M-P) invasive breast carcinomas are shown in Figure 1. Additional file 1 shows images of tissue incubated with isotype control antibodies.

\section{Tumour endothelial-FAK expression and relation with clinicopathological factors}

There was no significant correlation between endothelialFAK expression and patient age at presentation or tumour size (Table 2). Significantly higher mean endothelial FAK scores were seen in grade 3 tumours $(p=0.008)$, ER negative tumours $(\mathrm{p}=0.005)$, PR negative tumours $(\mathrm{p}=0.002)$ and Her2 positive tumours $(p=0.022$, Table 3$)$. EndothelialFAK expression was higher in TN versus non-TN tumours $(p=0.043)$ and lower in luminal A versus non-luminal A tumours $(\mathrm{p}<0.001$, Table 3$)$. There were no significant differences in endothelial-FAK levels in primary tumours between lymph node positive and lymph node negative tumours, or between luminal B versus non-luminal B and Her2 positive versus non-Her2 positive sub-types, although the highest FAK scores were seen in the Her2 positive subtype (Table 3).

\section{FAK expression in tumour cells in relation to clinicopathological factors}

There was no significant correlation between tumour cell FAK expression and patient age at presentation or tumour size (Table 2). Significantly higher mean cancer cell FAK scores were seen in grade 3 tumours $(\mathrm{p}=0.001)$, ERnegative tumours $(p=0.013)$ and PR-negative tumours 
Table 1 Clinical, pathological and molecular features of the patient cohort

\begin{tabular}{|c|c|c|}
\hline Parameter & $\mathrm{N}$ & $\begin{array}{l}\text { Mean }(95 \% \mathrm{Cl}) / \\
\text { Percentage of cases (\%) }\end{array}$ \\
\hline Age & 148 & 56.6 years $(54.5-58.6)$ \\
\hline Tumour size & 149 & 26.6 mm (23.8-29.3) \\
\hline Tumour grade & 149 & \\
\hline 1 & 2 & 1 \\
\hline 2 & 56 & 38 \\
\hline 3 & 91 & 61 \\
\hline Lymph node involvement & 145 & \\
\hline Yes & 69 & 48 \\
\hline No & 76 & 52 \\
\hline ER status & 149 & \\
\hline Positive & 87 & 58 \\
\hline Negative & 62 & 42 \\
\hline PR status & 149 & \\
\hline Positive & 79 & 53 \\
\hline Negative & 70 & 47 \\
\hline Her2 status & 149 & \\
\hline Positive & 12 & 8 \\
\hline Negative & 137 & 92 \\
\hline Molecular sub-type & 149 & \\
\hline Luminal A & 56 & 38 \\
\hline Luminal B & 31 & 21 \\
\hline Her2 positive & 12 & 8 \\
\hline $\mathrm{TN}$ & 50 & 33 \\
\hline
\end{tabular}

Abbreviations; $C l=$ confidence interval, $E R=$ estrogen receptor, $P R=$ progesterone receptor, $T N=$ triple negative.

$(\mathrm{p}=0.048$, Table 3). Tumour cell FAK expression was significantly higher in TN versus non-TN tumours $(\mathrm{p}=0.033)$ and lower in luminal A versus non-luminal A tumours $(\mathrm{p}=0.001$, Table 3$)$. There was no significant difference in cancer cell FAK scores between tumours with and without lymph node involvement or between tumours with positive and negative Her2 status. As with endothelial-FAK expression, there was no significant difference between the luminal B versus non-luminal B and Her2 versus non-Her2 molecular sub-types although again, the Her2 positive sub-type had the highest absolute FAK score (Table 3).

Correlation of FAK expression and established prognostic factors with the Luminal A sub-type - univariate regression

Given that the strongest statistical association in the sub-type analysis for both endothelial and tumour cell FAK expression was with lower scores in the luminal A versus non-luminal A tumours, we performed univariate regression analysis to identify other parameters that associated with luminal A tumours (Table 4). The 3 parameters that showed a significant association with luminal A tumours were tumour grade $(\mathrm{p}<0.001)$, FAK expression in tumour cells $(\mathrm{p}=0.001)$ and FAK expression in endothelial cells $(\mathrm{p}<0.001)$. These three factors had an odds ratio below 1 , confirming the association between low grade (grade 1/2) and low FAK expression in the luminal A sub-type (Table 4).

\section{Independent correlation of endothelial-FAK with the Luminal A sub-type}

To establish whether low endothelial-FAK expression was independently associated with luminal A tumours, we performed multivariate logistic regression. The parameters that associated with luminal A tumours at univariate analysis (tumour grade, endothelial-FAK expression and tumour cell FAK expression) were placed into the model in a step-wise fashion. The 2 parameters that remained in the model were tumour grade (OR 0.14, 95\% CI: 0.07-0.31; $\mathrm{p}<0.001)$ and endothelial-FAK expression (OR 0.03, 95\% CI: 0.01-0.25; $\mathrm{p}=0.001$, Table 5), suggesting that low endothelial-FAK expression is independently associated with the luminal A sub-type, even after taking tumour grade into account.

\section{Discussion}

The aim of the current study was to determine whether the levels of endothelial and tumour cell FAK correlate with clinicopathological characteristics in invasive breast carcinoma. While low expression of both endothelial and tumour cell FAK associated with luminal A tumours, only endothelial-FAK was independently associated with these tumours in multivariate analysis. This is the first study to demonstrate a relationship between endothelial-FAK expression and molecular sub-type in invasive breast cancer and our findings suggest that vascular expression of FAK is potentially more clinically relevant than tumour cell FAK in breast cancer.

The importance of FAK in angiogenesis and in cancer progression has been shown in several animal studies $[15,17,18,22-24]$. These studies in combination with the observed upregulation of FAK in several epithelial cancers has initiated the development of FAK inhibitors for the treatment of cancer [19].

Previous studies have investigated the significance of tumour cell FAK expression in invasive breast cancer [12,25-28]. Few of these studies looked specifically at molecular sub-type, but Yom et al. found that low tumour cell FAK expression correlated with the luminal A sub-type and higher levels with the luminal B and TN sub-types at univariate analysis [28] and our results corroborate these findings. In particular our finding of increased tumour cell and endothelial cell FAK in TN tumours suggest that FAK likely plays a role in the 


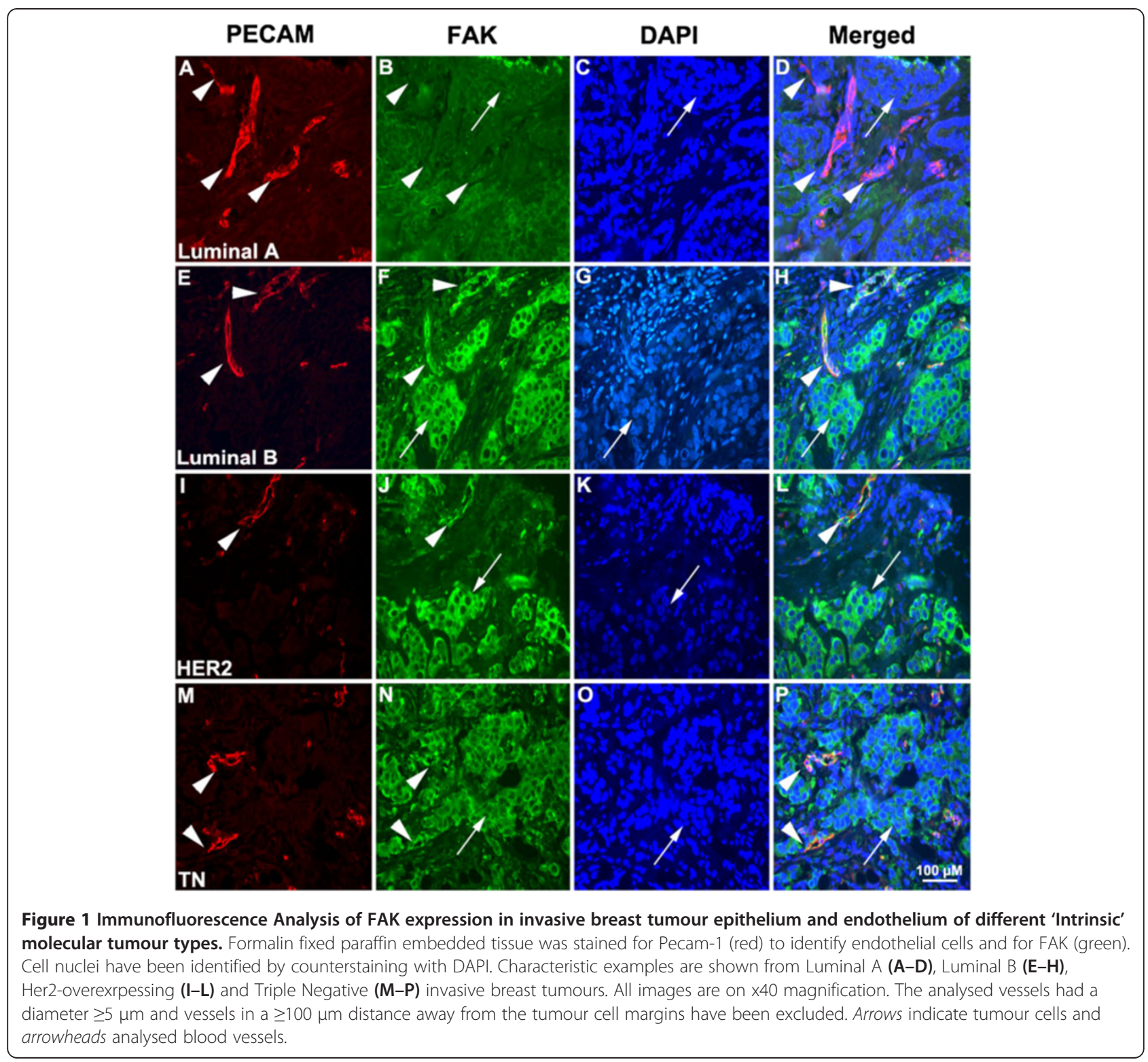

biology of these tumours. Predictably, our results regarding molecular sub-type are mirrored by our observations of the individual steroid receptors and Her2, where increased FAK expression correlated with ER and PR negativity and Her2 positivity. Others have shown comparable

Table 2 Correlation between FAK expression and prognostic factors (continuous variables)

\begin{tabular}{llll}
\hline FAK location & Parameter & Correlation co-efficient & p-value \\
\hline Vessels & Patient age & 0.096 & 0.246 \\
& Tumour size & 0.089 & 0.28 \\
\multirow{2}{*}{ Tumour cells } & Patient age & -0.138 & 0.094 \\
& Tumour size & 0.119 & 0.148 \\
\hline
\end{tabular}

Spearman's correlation co-efficient. findings [12,25,28]. Interestingly, in a study investigating the relationship between FAK and major signaling pathways in 162 node-negative breast cancers, elevated FAK expression correlated with Her2 over-expression and phospho-Src Tyr-215, prompting the authors to speculate that the activation of Akt via the FAK pathway contributes to the aggressive nature of Her2 over-expressing tumours [12]. Although we didn't find a statistically significant increase in endothelial/tumour cell FAK in the Her2 positive/luminal B sub-types (versus non-Her2 positive/ non-luminal B tumours) the absolute scores were higher in the former and the lack of significance may reflect the smaller patient numbers in these groups.

We found higher FAK expression (endothelial and tumour cell) in more aggressive grade 3 tumours, compared to 
Table 3 Association between FAK expression and prognostic factors (categorical variables)

\begin{tabular}{|c|c|c|c|}
\hline $\begin{array}{l}\text { FAK } \\
\text { location } \\
\end{array}$ & Parameter & $\begin{array}{l}\text { Mean FAK score } \\
(95 \% \mathrm{Cl})\end{array}$ & p-value \\
\hline \multirow[t]{20}{*}{ Vessels } & Tumour grade & & \\
\hline & 1 or 2 & $156.2(124.6-187.8)$ & \\
\hline & 3 & $200.2(177.9-222.6)$ & 0.008 \\
\hline & $\begin{array}{l}\text { Lymph node } \\
\text { involvement }\end{array}$ & & \\
\hline & Yes & $184.7(157.7-211.7)$ & \\
\hline & No & $179.6(152.8-206.5)$ & 0.765 \\
\hline & ER status & & \\
\hline & Positive & $161.3(139.9-184.6)$ & \\
\hline & Negative & $213.7(184.7-242.7)$ & 0.005 \\
\hline & PR status & & \\
\hline & Positive & $156.8(131.6-181.9)$ & \\
\hline & Negative & 212.8 (186.7-238.9) & 0.002 \\
\hline & Her2 status & & \\
\hline & Positive & $215.8(181.6-250.0)$ & \\
\hline & Negative & $169.8(148.0-191.6)$ & 0.022 \\
\hline & Molecular sub-typ & & \\
\hline & $\begin{array}{l}\text { Luminal A vs } \\
\text { Non-Luminal A }\end{array}$ & $\begin{array}{l}135.4(107.6-163.2) \text { vs } \\
211.8(189.0-234.6)\end{array}$ & $<0.001$ \\
\hline & $\begin{array}{l}\text { Luminal B vs } \\
\text { Non-Luminal B }\end{array}$ & $\begin{array}{l}208.0(169.1-246.9) \text { vs } \\
176.5(155.5-196.6)\end{array}$ & 0.130 \\
\hline & $\begin{array}{l}\text { Her2 positive vs } \\
\text { Non-Her2 }\end{array}$ & $\begin{array}{l}235.9 \text { (155.8-316) vs } \\
178.5(159.5-197.4)\end{array}$ & 0.121 \\
\hline & TN versus Non-TN & $\begin{array}{l}208.4(176.6-240.1) \text { vs } \\
170.3(147.6-193.0)\end{array}$ & 0.043 \\
\hline
\end{tabular}

Tumour Tumour grade

cells
Table 3 Association between FAK expression and prognostic factors (categorical variables) (Continued)

\begin{tabular}{lll}
\hline Luminal B vs & $5.0(4.4-5.6)$ vs & 0.408 \\
Non-Luminal B & $4.7(4.3-5.0)$ & \\
Her2 positive vs & $5.3(4.5-6.1)$ vs & 0.406 \\
Non-Her2 & $4.7(4.4-5.0)$ & \\
TN versus Non-TN & $\begin{array}{l}5.2(4.7-5.7) \text { vs } \\
\text { 4.5 (4.7-4.9) }\end{array}$ & 0.033 \\
&
\end{tabular}

Significant findings are in italics (Mann-Whitney test). Abbreviations: $\mathrm{Cl}=$ confidence interval.

grades 1 and 2. This is in keeping with other studies that have evaluated tumour cell FAK expression in tissue and cytology specimens from invasive breast cancers $[12,25,27,28]$. Tumour grade is an established poor prognostic factor in breast cancer [29] and given the association between high grade (and other prognostic factors such as ER/PR negativity) and high FAK expression it is entirely possible that FAK over-expression is associated with a poor outcome. To date, studies of outcome in relation to protein expression of FAK in human breast cancers have not demonstrated a significant effect on survival $[12,28]$, and larger studies with long term follow-up are needed. Of note, FAK amplification/high polysomy has been shown to be an independent poor prognostic factor for both overall and relapse-free survival [28].

A previous clinical trial looking at the VEGFR inhibitor, Sunitinib in unselected breast cancer patients has been unsuccessful [30]. Given the association between increased VEGF-receptor 2 expression in TN breast cancer [31], targeting TN breast cancer with Sunitinib or the anti-VEGF agent Bevacizumab may be a more effective approach and these clinical trials are now ongoing [30,32]. Likewise, our results suggest that clinical trials should consider focusing on non-luminal A tumours in the evaluation of FAK inhibitors for the treatment of breast cancer. Moreover, since the expression of FAK is not limited to a single cancer compartment effective inhibition of FAK signaling is particularly appealing.

$5.1(4.7-5.4)$

$4.5(4.0-5.0)$

0.249

ER status

Positive

$4.4(4.0-4.9)$

Negative

$5.2(4.8-5.6)$

0.013

PR status

Positive

$4.4(4.0-4.9)$

Negative

$5.1(4.7-5.5)$

0.048

Her2 status

Positive

$5.1(4.6-5.6)$

Negative

$4.6(4.2-5.0)$

0.215

Molecular sub-type

Luminal A vs

Non-Luminal A
Table 4 Association between prognostic factors, FAK expression and the luminal $A$ sub-type

\begin{tabular}{llll}
\hline Parameter & LR Chi Square & OR $(\mathbf{9 5} \%$ Cl) & p-value \\
\hline Age at diagnosis & 11.12 & $1.01(0.99-1.04)$ & 0.413 \\
Tumour size & 0.05 & $1.00(0.98-1.02)$ & 0.823 \\
Tumour grade & 32.03 & $0.13(0.06-0.27)$ & $<0.001$ \\
Lymph node status & 2.06 & $0.61(0.31-1.20)$ & 0.154 \\
FAK tumour cells & 11.41 & $0.11(0.03-0.42)$ & 0.001 \\
FAK vessels & 17.11 & $0.02(0.01-014)$ & $<0.001$ \\
\hline
\end{tabular}

Significant findings are in italics (univariate logistic regression). Abbreviations: $L R=$ likelihood ratio, $O R=$ odds ratio, $C l=$ confidence interval 
Table 5 Multivariate model containing parameters predictive of the luminal A sub-type

\begin{tabular}{lllll}
\hline Parameter & $\begin{array}{l}\text { Stepwise } \\
\text { entry }\end{array}$ & LR Chi Square & OR (95\% Cl) & p-value \\
\hline Tumour Grade & 1 & 32.03 & $0.14(0.07-0.31)$ & $<0.001$ \\
FAK vessels & 2 & 11.31 & $0.03(0.01-0.25)$ & 0.001 \\
\hline
\end{tabular}

Multivariate logistic regression with stepwise forward entry. Abbreviations:

$\mathrm{LR}=$ likelihood ratio, $\mathrm{OR}=$ odds ratio, $\mathrm{Cl}=$ confidence interval.

\section{Conclusion}

In conclusion, this study is the first to analyse endothelialassociated FAK expression in human breast tumour samples. We demonstrate that lower endothelial FAK expression is independently associated with the luminal A sub-type, and conversely, high endothelial and tumour cell FAK expression correlates with the poorer prognosis non-luminal A tumours and other established poor prognostic factors. The association between high FAK levels and TN tumours is worthy of further investigation in a larger series to establish the prognostic significance of tumour/endothelial FAK in the TN/BL sub-type. Overall our findings strengthen the argument for investigating the role of FAK inhibitors as a novel treatment for poor prognosis breast cancer sub-types and identify endothelial expression of the protein as a potentially useful biomarker for future clinical studies.

\section{Additional file}

Additional file 1: Negative controls for immunofluorescence staining. Formalin fixed paraffin embedded IDC tissue was incubated with rabbit lgG and mouse IgG antibodies, followed by anti-rabbit (Alexa 546; red) and anti-mouse (Alexa-488; green) secondary antibodies. Cell nuclei have been identified by counterstaining with DAPI.

\section{Competing interests}

The authors declare that they have no competing interests.

\section{Authors' contributions}

ANA, VP and KHD designed the experiments and the paper. $U \sqcup$ provided human tissue sections. $\mathrm{CMH}$ carried out the statistical analysis and comparisons. GE cut sections for analysis. ANA, CMH, JLJ and KHD wrote the paper. All authors read and approved the final manuscript.

\section{Acknowledgements}

This work was funded by Cancer Research UK programme grant A12007. $\mathrm{CMH}$ was funded by a Cancer Research UK Clinical Research Fellowship and \lrcorner$\lrcorner$ was funded by the Breast Cancer Campaign Tissue Bank.

\section{Author details}

${ }^{1}$ Adhesion and Angiogenesis Laboratory, Centre for Tumour Biology, Barts Cancer Institute - a CR-UK Centre of Excellence, Queen Mary University of London, John Vane Science Centre, Charterhouse Square, London EC1M $6 \mathrm{BQ}$, UK. ${ }^{2}$ Breast Group, Centre for Tumour Biology, Barts Cancer Institute - a CR-UK Centre of Excellence, Queen Mary University of London, John Vane Science Centre, Charterhouse Square, London EC1M 6BQ, UK. ${ }^{3}$ Vascular Adhesion Lab, BSRC Al. Fleming, 34 Fleming str., 16672 Vari Athens, Greece.

Received: 16 September 2013 Accepted: 25 March 2014

Published: 2 April 2014

\section{References}

1. Perou CM, Sørlie T, Eisen MB, van de Rijn M, Jeffrey SS, Rees CA, Pollack JR, Ross DT, Johnsen H, Akslen LA, Fluge O, Pergamenschikov A, Williams C, Zhu SX, Lønning PE, Børresen-Dale AL, Brown PO, Botstein D: Molecular portraits of human breast tumours. Nature 2000, 406:747-752.

2. Sørlie T, Perou CM, Tibshirani R, Aas T, Geisler S, Johnsen H, Hastie T, Eisen MB, van de Rijn M, Jeffrey SS, Thorsen T, Quist H, Matese JC, Brown PO, Botstein D, Lønning PE, Børresen-Dale AL: Gene expression patterns of breast carcinomas distinguish tumour subclasses with clinical implications. Proc Natl Acad Sci U S A 2001, 98:10869-10874.

3. Polyak K: Heterogeneity in breast cancer. J Clin Invest 2011, 121:3786-3788.

4. Cheang MC, Voduc D, Bajdik C, Leung S, McKinney S, Chia SK, Perou CM, Nielsen TO: Basal-like breast cancer defined by five biomarkers has superior prognostic value than triple-negative phenotype. Clin Cancer Res 2008, 14:1368-1376.

5. Rakha EA, Elsheikh SE, Aleskandarany MA, Habashi HO, Green AR, Powe DG, El-Sayed ME, Benhasouna A, Brunet JS, Akslen LA, Evans AJ, Blamey R, ReisFilho JS, Foulkes WD, Ellis IO: Triple-negative breast cancer: distinguishing between basal and nonbasal sub-types. Clin Cancer Res 2009, 15:2302-2310.

6. Lechertier T, Hodivala-Dilke K: Focal adhesion kinase and tumour angiogenesis. J Pathol 2012, 226:404-412.

7. Luo M, Guan JL: Focal adhesion kinase: a prominent determinant in breast cancer initiation, progression and metastasis. Cancer Lett 2010, 289:127-139.

8. Ji HF, Pang D, Fu SB, Jin Y, Yao L, Qi JP, Bai J: Overexpression of focal adhesion kinase correlates with increased lymph node metastasis and poor prognosis in non-small-cell lung cancer. J Cancer Res Clin Oncol 2013, 139:429-435.

9. Lightfoot HM Jr, Lark A, Livasy CA, Moore DT, Cowan D, Dressler L, Craven RJ, Cance WG: Upregulation of focal adhesion kinase (FAK) expression in ductal carcinoma in situ (DCIS) is an early event in breast tumourigenesis. Breast Cancer Res Treat 2004, 88:109-116.

10. Oktay MH, Oktay K, Hamele-Bena D, Buyuk A, Koss LG: Focal adhesion kinase as a marker of malignant phenotype in breast and cervical carcinomas. Hum Pathol 2003, 34:240-245.

11. Owens LV, Xu L, Craven RJ, Dent GA, Weiner TM, Kornberg L, Liu ET, Cance WG: Overexpression of the focal adhesion kinase (p125FAK) in invasive human tumours. Cancer Res 1995, 55:2752-2755.

12. Schmitz KJ, Grabellus F, Callies R, Otterbach F, Wohlschlaeger J, Levkau B, Kimmig R, Schmid KW, Baba HA: High expression of focal adhesion kinase ( $p 125 F A K$ ) in node-negative breast cancer is related to overexpression of HER-2/neu and activated Akt kinase but does not predict outcome. Breast Cancer Res 2005, 7:R194-203.

13. Madan R, Smolkin MB, Cocker R, Fayyad R, Oktay MH: Focal adhesion proteins as markers of malignant transformation and prognostic indicators in breast carcinoma. Hum Pathol 2006, 37:9-15.

14. Haskell H, Natarajan M, Hecker TP, Ding Q, Stewart J, Grammer R, Gladson $\mathrm{CL}$ : Focal adhesion kinase is expressed in the angiogenic blood vessels of malignant astrocytic tumours in vivo and promotes capillary tube formation of brain microvascular endothelial cells. Clin Cancer Res 2003, 9:2157-2165.

15. McLean GW, Komiyama NH, Serrels B, Asano H, Reynolds L, Conti F, Hodivala-Dilke K, Metzger D, Chambon P, Grant SG, Frame MC: Specific deletion of focal adhesion kinase suppresses tumour formation and blocks malignant progression. Genes Dev 2004, 18:2998-3003.

16. Chen XL, Nam JO, Jean C, Lawson C, Walsh CT, Goka E, Lim ST, Tomar A, Tancioni I, Uryu S, Guan JL, Acevedo LM, Weis SM, Cheresh DA, Schlaepfer DD: VEGF-induced vascular permeability is mediated by FAK. Dev Cell 2012, 22:146-157.

17. Tavora B, Batista S, Reynolds LE, Jadeja S, Robinson S, Kostourou V, Hart Fruttiger M, Parsons M, Hodivala-Dilke KM: Endothelial FAK is required for tumour angiogenesis. EMBO Mol Med 2010, 2:516-528.

18. Kostourou V, Lechertier T, Reynolds LE, Lees DM, Baker M, Jones DT, Tavora B, Ramjaun AR, Birdsey GM, Robinson SD, Parsons M, Randi AM, Hart IR, Hodivala-Dilke K: FAK-heterozygous mice display enhanced tumour angiogenesis. Nat Commun 2020, 2013:4.

19. Schultze A, Fiedler W: Clinical importance and potential use of small molecule inhibitors of focal adhesion kinase. Anticancer Agents Med Chem 2011, 11:593-599. 
20. Leong AS, Zhuang Z: The changing role of pathology in breast cancer diagnosis and treatment. Pathobiology 2011, 78:99-114.

21. McShane LM1, Altman DG, Sauerbrei W, Taube SE, Gion M, Clark GM: Statistics Subcommittee of the NCI-EORTC Working Group on Cancer Diagnostics: REporting recommendations for tumour MARKer prognostic studies (REMARK). Br J Cancer 2005, 93(4):387-391.

22. Braren $R$, Hu H, Kim YH, Beggs $H E$, Reichardt LF, Wang R: Endothelial FAK is essential for vascular network stability, cell survival, and lamellipodial formation. J Cell Biol 2006, 172:151-162.

23. Ilic D, Furuta Y, Kanazawa S, Takeda N, Sobue K, Nakatsuji N, Nomura S, Fujimoto J, Okada M, Yamamoto T: Reduced cell motility and enhanced focal adhesion contact formation in cells from FAK-deficient mice. Nature 1995, 377:539-544.

24. Shen TL, Park AY, Alcaraz A, Peng X, Jang I, Koni P, Flavell RA, Gu H, Guan $\mathrm{JL}$ : Conditional knockout of focal adhesion kinase in endothelial cells reveals its role in angiogenesis and vascular development in late embryogenesis. J Cell Biol 2005, 169:941-952.

25. Lark AL, Livasy CA, Dressler L, Moore DT, Millikan RC, Geradts J, lacocca M, Cowan D, Little D, Craven RJ, Cance W: High focal adhesion kinase expression in invasive breast carcinomas is associated with an aggressive phenotype. Mod Pathol 2005, 18:1289-1294.

26. Golubovskaya VM, Conway-Dorsey K, Edmiston SN, Tse CK, Lark AA, Livasy CA, Moore D, Millikan RC, Cance WG: FAK overexpression and p53 mutations are highly correlated in human breast cancer. Int I Cancer 2009, 125:1735-1738.

27. Theocharis SE, Klijanienko JT, Padoy E, Athanassiou S, Sastre-Garau XX: Focal adhesion kinase (FAK) immunocytochemical expression in breast ductal invasive carcinoma (DIC): correlation with clinicopathological parameters and tumour proliferative capacity. Med Sci Monit 2009, 15:BR221-BR226.

28. Yom CK, Noh DY, Kim WH, Kim HS: Clinical significance of high focal adhesion kinase gene copy number and overexpression in invasive breast cancer. Breast Cancer Res Treat 2011, 128:647-655.

29. Elston CW, Ellis IO: Pathological prognostic factors in breast cancer. I. The value of histological grade in breast cancer: experience from a large study with long-term follow-up. Histopathology 1991, 19:403-410.

30. De Laurentiis M, Cianniello D, Caputo R, Stanzione B, Arpino G, Cinieri S, Lorusso V, De Placido S: Treatment of triple negative breast cancer (TNBC): current options and future perspectives. Cancer Treat Rev 2010, 36:S80-S86.

31. Rydén L, Jirström K, Haglund M, Stål O, Fernö M: Epidermal growth factor receptor and vascular endothelial growth factor receptor 2 are specific biomarkers in triple-negative breast cancer. Results from a controlled randomized trial with long-term follow-up. Breast Cancer Res Treat 2010, 120:491-498.

32. Perou CM: Molecular stratification of triple-negative breast cancers. Oncologist 2011, 16:61-70.

doi:10.1186/1471-2407-14-237

Cite this article as: Alexopoulou et al:: Tumour-associated endothelialFAK correlated with molecular sub-type and prognostic factors in invasive breast cancer. BMC Cancer 2014 14:237.

\section{Submit your next manuscript to BioMed Central and take full advantage of:}

- Convenient online submission

- Thorough peer review

- No space constraints or color figure charges

- Immediate publication on acceptance

- Inclusion in PubMed, CAS, Scopus and Google Scholar

- Research which is freely available for redistribution

Submit your manuscript at www.biomedcentral.com/submit 